\title{
Puzzles about the "Crowdfunding" in Cultural Industry and Its Ecological Countermeasures
}

\author{
Xiaoji Sun, Qingjun Meng \\ Business School of Hohai University, Nanjing, China \\ Email: sunxiaojisun@163.com
}

Received 29 March 2015; accepted 28 June 2015; published 1 July 2015

\begin{abstract}
With the development of economy and people's concern about cultural industry, the crowdfunding in cultural industry has welcomed its development opportunity, and many crowdfunding platforms have been developed. However, there are some puzzles when the cultural industry is using the crowdfunding platform to get finance, such as lacking of laws and regulations to safeguard the crowdfunding in cultural industry, and the crowdfunding platform hasn't found its ecological niche. Therefore, we need to take some ecological countermeasures, such as consummating related laws to construct a favorable ecological environment, establishing ecological niche for the crowdfunding platform of cultural industry, and helping cultural industry become powerful.
\end{abstract}

\section{Keywords}

Cultural Industry, Crowdfunding, Risk, Ecological Countermeasures

\section{Introduction}

The crowdfunding in cultural industry is a process for cultural industry to get finance by making use of crowdfunding model. This word was originated from an English word "crowdfunding", which was the integration of "crowd sourcing" and "micro financing". The meaning of crowdfunding is the financing from the public by making use of the internet-financing platform, especially the micro fund raising with the purpose of assisting individuals, public welfare charity organizations, or business enterprises [1]. Crowdfunding has four kinds of models: donate-based crowdfunding, reward-based crowdfunding, equity-based crowdfunding, and lending-based crowdfunding. The scope of cultural crowdfunding can be roughly divided into the following aspects: independent film, creative art, publication, electronic games, pop music, citizen news, and health communication. Cultural industry has become one of the important mainstays for the economic development of China, but its financing problem is very prominent. Most small and micro-sized companies in cultural industry lack of tangible assets. Their culturally intangible assets are hard to accord with the bank's requirement for mortgage finance. However, these cultural enterprises are hard to finance from capital market, while the appearance of crowdfunding can 
open a new path for low-cost financing.

In other countries, especially in America, the development of crowdfunding in cultural industry is very fast. In 2006, Michael Sullivan established a financing platform, which brought crowdfunding to our horizon for the first time. Now, there are about 450 crowdfunding platforms in the world, and the Kickstarter website established in April 2009 enjoyed the largest fame, with its total financing amount exceeding 1 billion [2]. At present, the government, investment fund, and individuals who are willing to make investment get more and more concern on cultural crowdfunding, and domestic market about cultural crowdfunding is facing new opportunities for development. However, cultural crowdfunding has many problems to be studied and solved out, as the academic circle and enterprises are much concerned about it. For instance, the country lacks of laws and regulations on safeguarding the crowdfunding in cultural industry; the credit rank for cultural crowdfunding platform is very low, and lacks effective protection for investors; cultural products lack creativeness, so they cannot attract enough investment; crowdfunding in cultural industry lacks cooperators.

\section{Related Studies}

The occurring of cultural crowdfunding has aroused the widespread concern in the theoretical circle, while the continuous development of theoretical research has infused new energy to the development of cultural crowdfunding. Wu (2014) thought that crowdfunding could maintain the rights of investors on one hand, and also prevent systematic risk, as well as promote the formation of capital on the other hand. Meanwhile, in order to better achieve this target, he raised a series of rules for fund raisers, investors, and the crowdfunding platform. He also suggested establishing a unified and comprehensive social credit system at the national level, so as to enhance the cost of bad faith [3]. Fan (2013) analyzed the fundraiser, intermediary institution, and provider in the business model. Meanwhile, through analyzing the value discovery, value match, and value obtaining of the business model in crowdfunding, he summarized that the advantage of the business model in crowdfunding is to promote micro enterprises and stimulate "grassroots" innovation. His research also pointed out that no matter in China or other countries, cultural innovation in the crowdfunding platform occupies the largest part. Taking China's Roll Call as an example, $60 \%-70 \%$ belongs to cultural creative industry [4]. Wang (2014) maintained that as a new thing, crowdfunding implies many risks. For instance, the legal risk of investment crowdfunding behavior; because the product technology is not mature, lacking of technical standard, the technical lifespan is uncertain, and other technical risks; because of the credit risk that brought by information asymmetry; as well as the management risks that caused by the low quality of the originators or managers. Meanwhile, the author pointed out that we should standardize this industry from various perspectives, like policy, and the main body of crowdfunding, to reduce the risk of crowdfunding and promote the healthy development of crowdfunding [5].

Zhang and Zhou (2006) viewed that investment and financing in cultural industry are the main strength to push forward the development of cultural industry, while the problem of investment and financing is the bottleneck for the development of cultural industry. On one hand, cultural industry has huge investment and financing space, such as demand space, content space, scale space; on the other hand, the investment in cultural industry is insufficient, the efficiency for investment and financing is low, and it lacks of investment and financing channels. The reasons for this problem includes the lacking behind of government management philosophy, unsound policies in cultural industry, imperfect laws and regulations, as well as low scientific and technological content in the object of investment and financing (cultural products or service). In order to solve this problem, they proposed a diversified investment and financing system, which is "combined by the country and people, guided by national asset, and take the public capital as the main part". Meanwhile, they proposed related countermeasures and suggestions to promote the rapid development of China's cultural industry [6]. The release conference of "Cultural China: Index for China's Cultural Industry" (2014) thought that cultural industry was entering a new internet thinking era. "In 2014, the internet thinking has extensively influenced the whole cultural creative industry, and it has played a huge role in enhancing the cultural creative industry." Chen Shaofeng (2014) showed that the structure of China's cultural enterprises has undergone huge changes, and many traditional cultural industries are moving or have moved to the internet. Internet enterprises are dominating the merging resource integration of cultural industry. By the end of 2016, internet cultural industry will occupy $70 \%$; traditional media occupies 10\%; artistic products, arts and handcrafts, as well as entertainment device will occupy 10\%; experiencing (film, performance, Chinese folk art forms, karaoke) entertainment and theme park, or design will oc- 
cupy another $10 \%$.

Zhang Xiaoming (2014) thought that the cultural industry has expressed a spectacle of industrial integration, and it has represented the integration of network economy for high technology. He maintained that for the development of national economy, for the promotion of the macroeconomic transition, for the promotion of new technology, the integration not only occurs in cultural industry between industries, but also between cultural industry and all concerned trades of national economy. Wei Pengju (2014) expressed that the combination between cultural industry and the internet will undoubtedly help us fully recognize its huge function for driving the upgrade of cultural industry. With the development of the internet, the increase of netizens, the internet's penetration into economy and life, cultural industry will seek profound upgrading if it can ride this express bus of internet. Aitamurto (2011) deemed that crowdfunding news is a way to make news through utilizing collective wisdom and money. Crowdfunding mainly solves out the problem of insufficient capital during the process of making news. She pointed out that during the process of collecting fund to make news, and from the perspective of a journalist, there is a close connection between journalists and funders, which has changed the relationship between journalists and the audience through the process of gathering capital [7].

To sum up, scholars have formed solid recognition about the model of crowdfunding, existing risks, as well as the combination between cultural industry and the internet. Nevertheless, they still need further study on the well combination between China's cultural industry and crowdfunding.

\section{Projects and Research Methods of Crowdfunding in Cultural Industry}

\subsection{Projects and Platforms of Crowdfunding in Cultural Industry}

Crowdfunding model has similar behaviors in the history. In the 17th century, British poet Alexander Pope adopted the crowdfunding model when translating "Homer's Iliad". Those who assisted him to translate the book got a "Homer's Iliad" with their names respectively. In 1784, Mozart accomplished the three piano concertos with similar method and played it in the Vienna Hall. Even the famous Statue of Liberty in America was completed in 1885 through crowdfunding. Nowadays, it yields unusually brilliantresults through internet technology. Its projects and crowdfunding platforms mainly include the following:

\subsubsection{Gaming Projects of Cultural Crowdfunding}

Gambitious is a crowdfunding platform in the Netherlands that exclusively develops games. This website connects loyal game players with game developers. Game players can support their favorite electronic gaming creativeness, offer sponsor, and make related topics about their supportive games before these games are released. Meanwhile, European supporters can purchase the stock right of their supportive games.

\subsubsection{Cartoon Projects of Cultural Crowdfunding}

American crowdfunding website Kickstarter has successfully gathered fund for independent animation directors like Bill Plympton. Japanese studio Ghibli gathered fund for the animation film "Tree of Hope" through crowdfunding. The Name Call once gathered 339,480 yuan for the animation work "Go away Mr. Tumour". The crowdfunding net gathered 1.373 million yuan for the original animation film "One Hundred Thousand Bad Jokes" in China in June 2013, with the participants exceeding 5533.

\subsubsection{Music Project of Cultural Crowdfunding}

Musikid cooperated with Tan Weiwei. First step, sending postcards for free, so that users can listen to the music through scanning the two-dimensional code on the postcard; second step, preserve the disk and sell T-shirts with the theme of the new album on it. Then, it provides funny experience that one can work a day together with stars in the recording studio, to let fans get closer to stars.

\subsubsection{Publication Projects of Cultural Crowdfunding}

Its projects include "What May Be Possible in Your Life" with personalized custom and limited printing amount; the "Letters from Father Christmas" that you can read together with stars; the album of "Empresses in the Palace" that related to film culture; the "Social Dividend" that can take part in afternoon tea, training, and consultation; the "New Technology and New Rules" that can have lunch with celebrities by making use of fans effect; and "A 
New Day" of a worker poet that publishes social welfare.

\subsubsection{Crowdfunding Platform in Domestic Cultural Industry}

The project of "Name Call" involves the following platforms: design, science, music, film, cartoon, publication, games, and photograph. It is transforming into the first issue and trial for intellectual hardware. "Tmeng.com" project only involves micro-film, which strives to be the largest new media film platform. "Crowdfunding.com" project involves science, public welfare, publication, entertainment, art, and agriculture, which strives to be a pioneer of domestic crowdfunding website.

\subsection{Research Method: The Theory of "Ecological Niche"}

"Ecological niche" is an important theory in ecology. It refers to the position and role of species in the ecological system. The existent in the nature has its ecological niche. In its own ecological niche, it can give better performance to its competitiveness and utilize surrounding resources, to earn more spaces for its existence. For instance, the ecological niche of a hawk is the sky, while the ecological niche for fish is the water. Crowdfunding platform is a new industry or "species" in financial area. Its development is interfered by laws, regulations, competitions, and public opinions. Cultural industry and crowdfunding cooperation have great potential for their development.

\section{Puzzles of Crowdfunding in Cultural Industry}

\subsection{Crowdfunding Environment in Cultural Industry Lacks of Legal Support}

The basis for the improvement of ecological environment in cultural crowdfunding is a series of related and consummated regulations, otherwise these markets will walk with great difficulty. For example, related laws on the crowdfunding of stock right are not sound. Under the restriction of "Securities Law", "Corporate Law", and "Criminal Law", these actions are in the grey zone of laws, which may be easily classified into the scope of illegal fund raising. Although there are concerned stipulations, it still has some risks. For instance, although it has standardized the act of equity crowdfunding, it cannot disclose for publicity, while investors are only specific objects, so it has increased difficulty for cultural crowdfunding. Moreover, the information can be sent to specific objects without no more than 200 people. In this way, the gathered capital is limited, or the investment for each investor is large, so investors need to undertake great risk. For example, on December 18, 2014, the website of securities of China issued "Management Methods for Financing Management of Private Equity Crowdfunding (Trial) (Draft)", which specifies that equity crowdfunding should adopt non-public way, and satisfy related regulations on non-public issuance in Article 10 of "Securities Law". It requires that: first, investors must be specific objects, namely real name registered users that comply with the regulations in "Management Methods" that verified by equity crowdfunding platform; second, accumulated investors should no more than 200; third, equity crowdfunding platform can only recommend project information to those real name registered users. However, equity crowdfunding platform and financiers cannot make public propaganda, recommendation, or persuasion.

\subsection{Not Finding Out the Ecological Niche in Crowdfunding Platform}

Although there are many crowdfunding platforms in cultural industry, the development of many platforms is still unclear or lacking of core competitiveness. As modern communication science is more and more developed, people can obtain cultural resources through the internet with low cost. Therefore, the willing to pay for a cultural product is gradually reduced. From this aspect, people avoid crowdfunding platform in cultural industry, while the motivation of using internet to obtain cultural resources is supported. If the crowdfunding in cultural industry is a form that creators accept capital from investors, and then they will feedback their works to investors, what is the difference between it and the purchasing behavior, or even its profit is less than that of purchasing. It adds difficulty to the development of crowdfunding platform in cultural industry. Many platforms can hardly find the market space suitable for their existence, which is the space suitable for the ecological niche of their development. What's worse, some even become the weak in the ecological niche for lacking of any specialty. Some cultural projects of crowdfunding have the problem of infringement. For example, the originality of an animation film project that released on Kickstarter plagiarized from a rewarded French work, while crowdfunding platform didn't notice it in time. Some crowdfunding platforms also extended their businesses, which 
not only consist of cultural crowdfunding, but also other industries. This may separate the resources that were originally few, so that it will lack of its competitive edge for not being targeted.

\subsection{Cultural Industry Is a Weaker in Ecological Niche}

Common investors lack of judgment for project risk, and they are usually attracted by the package or committed return of crowdfunding platform, and then make wrong selections. These behaviors will be easily given the accusation of illegal funding. For instance, in 2013, Beijing Meiwei Cultural Communication Corporation transferred its "IPO" on Taobao through selling membership card with the stock right as a gift, and it transferred 161 IPOs in public within over 10 days through Taobao. However, it was listed as "the crime of illegally issuing stock rights in public" by CSRC. Investors did not know whether their final cultural products are satisfied before the investment, and the capital has time value. If they pay the capital in advance, they will suffer a loss for only obtaining unsatisfied products at last. Compared with other investment and financing products, cultural crowdfunding has little return, but large risk, so it doesn't have large attraction for investors. If one only wants to gain returns of money, cultural crowdfunding will not be his best choice. Taking Alibaba's"Entertainment Investment Fund" as an example, the predicted returns ratio is $7 \%$, but it only released 4 films and one game at the early stage. The film investment is $100 y u a n$ for each and the game is 50 yuan for each. Meanwhile, everyone can only buy 2 shares. That is to say, one person can investment 900 yuan at most. If all these projects can reach the predicted returns ratio of $7 \%$, the income will be no more than 63 yuan.

\subsection{Cultural Industry Lacks of Cooperators in Ecological Niche}

Ecology views that most living creatures depend on mutual benefit and common existence, and they have formed the effect of coevolution [8]. Likely, the development of cultural industry cannot be away from the cooperation of multi-main bodies. Only with the common participation of creators, directors, actors, crowdfunding platforms, investors, and consumers in cultural industry, can cultural products full of creativeness and satisfy the real needs of the public. On the contrary, if creators work behind closed doors, they will not know the market requirement, lack of marketing promotion experience, and be buried in the numerous cultural products. Therefore, they will not be known to others, or even attract investment from others. For example, although the publication crowdfunding platform Ten Pages that initiated by some unknown authors has successfully published 66 books, 28 books were sold out less than 500 rolls each. Therefore, we can see that the product quality is very low, and the creativeness lacks of market appeal. Taking Tmeng.com as another example, it once adopted low cost strategy in terms of the playwright, director, circulation director, photographer, actor, clothing, and background of micro films, which cannot ensure the quality of micro films, or push forward the investment through fans. On the recommendation page, we can see that the page view number of some micro films that have one or two months left is even less than 1000 , the comment number is in one digit, and the investment amount is even less. It can be said that the cultural crowdfunding without cooperators is hard to seek existence or development in complicated and changing economic environment.

\subsection{The Values of Cultural Projects Need to Be Adjusted}

Although the ticket office of "Tiny Time3" that released by "Entertainment Investment Fund" has exceeded 522 million, the "Gold Rush", which is the first film financing product for "Baifa Youxi" (a product from Baidu Finance), quitted out roughly for merely 30 million tickets. Why there are so many differences between these two? "Tiny Time3" depicts the life that dreamed by many young people: a glass villa in the center of a flourishing city like Shanghai, decent job, wealthy and handsome boyfriend, comfortable and luxurious life. This cultural product caters to the vulgar values of young people. Although it gained short-term economic benefit, this luxurious and wasting value was an extremely bad guide to teenagers, and it may lead to bad aftermath in the future. In order to gain profit for the financing of cultural projects as soon as possible, some cultural crowdfunding platforms induce cultural works lean to the entertainment culture that can please people's sensory needs. This scale and mechanical cultural production way has boosted vulgar, repeated, and gaming hedonism culture. The entertainment culture that lacks of aesthetic value changes aesthetics to moderate consumption. Hedonism culture will gradually disturb the regular order of cultural development. Through the examination of time, it will not get the final confirm of people, or even the confirm from the social mainstay. 


\section{Ecological Countermeasures to Construct Favorable Environment for Crowdfunding in Cultural Industry}

\subsection{Consummate Related Laws to Construct Favorable Ecological Environment}

Environment has vital influence for living creatures. Likely, with regard to cultural crowdfunding, national laws and regulations are the basis for its production and development. In terms of the issue that crowdfunding, especially equity crowdfunding is easily given the name of illegal financing, its application scope should be condensed appropriately. In order to help the crowdfunding in China's cultural industry get finance successfully, our country should learn from America with selection, gradually release the restriction of publicizing to "specific objects", adjust the restriction for the number of private stock holders, expand the group of investors, strengthen people's education about investment, risk, and finance, and also consummate the protection mechanism for the rights of small stock holders. Only in this way, can we help the financing of cultural industry and protect the rights of investors from being infringed. Through relaxing the requirements for financial supervision, American "Jumpstart Our Business Startups Act" (JOBS Act for short, 2012) encouraged the financing of small and micro enterprises in America. However, this action is worth to be learned. JOBS Act exempted the restriction of not opening its publicity to the public for unlisted companies when they are collecting fund through private placement. Only if investors are certified investors, they can make publicity in the public. Moreover, this act has relaxed the information disclosure obligation of listed enterprises and those enterprises to be listed. It allowed the capital gathering through the network platform, and increased the number of people who will register the listed company through SEC to 2000 from 500. Recently, the "Guidance and Opinions on Developing Common Creative Space and Promoting Common Creative Business from the State Council" $(2015,3.11)$ proposed many opinions, such as consummating pioneering financing mechanism, developing the pilot area for internet equity crowdfunding. All these measures will help cultural crowdfunding build a favorable ecological environment.

\subsection{Crowdfunding Platforms in Cultural Industry Have Their Ecological Niches}

If the crowdfunding platform in cultural industry wants to exist in the market, it must find out its ecological niche, to avoid its failure in the competition. Cultural financing is a favorable choice for related crowdfunding platforms. Although crowdfunding platform has many advantages like low financing cost and low threshold, it must screen those cultural products that are deeply favored by the public and have great creativeness, or even let investors take part in the creation process, to change the status of not willing to pay for the product. Because some cultural crowdfunding platforms cannot offer large investment return to investors, it can make up for this weakness. For instance, the publication crowdfunding platform Unbound (bulk book) that created in London expressed this idea in its operation concept. Through crowdfunding, it provides more interactions to authors and readers, so that they, not the publishers, will decide the content for the topic of the book. With screening from the website, authors can write out their opinions about their topic selection, and those who are interested in it will make investment. The investment amount can only be the price of the book, or for the purpose of getting a book with his or her own name, or pay extra money for the special right of attending the press conference together with the author. Some other platforms implement the principle of "action first payment second". These platforms commit to investors that when the project fails, and project initiator cannot make payment in time, the platform shall shoulder the responsibility of making the payment. Crowdfunding platforms should better focus on cultural industry or related industries, but not blindly expanding their business scopes to unrelated industries. For instance, Qingju Crowdfunding strives to create the first progressive crowdfunding platform in China. By making use of exclusive product funnel to screen projects and quality investors from product crowdfunding pool, it can gradually form excellent equity crowdfunding projects with quantified data, product by lot, as well as low risk and high return.

\subsection{Cultural Industry Become the Stronger of Ecological Niche}

There is full of competition in the nature, and the competition between species will promote the continuous evolution of species, and then make the nature full of energy. If there is no competition between species, it will stay at the disadvantaged position of ecological niche, or even suffer the risk of being replaced. If cultural industry wants to successfully cooperate with crowdfunding platform, its cultural projects must have its own characteristics, to make efficient financing. First, the project is of high quality. Cultural creation should be exclusive, with the content of independent thinking, but not plagiarizing from existing works. Meanwhile, it should avoid 
infringement, and prevent the harm on the benefit of investors. Creators should strive to enhance the quality of cultural products, and attract the eyes of investors through creativeness. When carrying forward the traditional culture, it should explore the way to increase interest, participation, entertainment, and knowledge, so that it can both carry forward the culture and insist on original creation. Second, it should cooperate with platforms, and strengthen the marketing promotion, product package, and sales channels, to enhance the concern from the media and the exposure of the project. In this way, it can attract the eyes of investors, and achieve the goal of financing. American Allan Karl spend three years on travelling around the world by riding a motorcycle, and he continuously released many dynamic travel notes through the World Rider blog, to interact with his fans. Based on this, he published a full color hardcover book, with the name of "Buddies: 3 Years, 5 Continents, 1 Motorcycle; Culture, Food, and Customs". Meanwhile, he got direct financing from fans through Kickstarter, finally got support from 435 people, and gathered $\$ 40,000$.

\subsection{Mutually Benefit Cooperation between Cultural Industry and Related Stakeholders}

In cultural industry, if it, film, music, publication, or activity, can joint with starts, and get support from fans economy, the financing for cultural crowdfunding will be easier. LeTV, a video website, jointed together with crowdfunding website and initiated the World Cup network sports activity. Meanwhile, it put the first crowdfunding project online----" I Sign Cristiano Ronaldo and You Make the Decision". It states that within stipulated term, if it can collect the support from 10,000 people (1 yuan from each person), the project will be successful, and then LeTV will sign Cristiano Ronaldo as the spokesperson of World Cup. At the meantime, all supporters will become a free member of LeTV, and have the opportunity to take part in a series of following activities. In this crowdfunding activity, LeTV, Crowdfunding website, Cristiano Ronaldo, and investors are benefited. First, in terms of the crowdfunding website, it can gain some income through this crowdfunding activity, and enhance its reputation through fame of LeTV and Cristiano Ronaldo. Second, in terms of investors, it is a great experience if they can help their favorite star to be the spokesperson, become a member of LeTV, and take part in activities only with 1yuan. As the largest profit maker, LeTV utilized the function of investigating potential users through the crowdfunding model, and warmed up for signing Cristiano Ronaldo as the spokesperson of World Cup. Meanwhile, it can push forward the program rating of World Cup, and accumulated users for officially signing Cristiano Ronaldo as the spokesperson of following activities. The rock singer Amanda Palmer collected over $\$ 1$ million for his new albums, books, and travels, and more than 2000 fans gave him support.

\subsection{Cultural Industry Should Have Positive Values}

Unlike other products, cultural product is a material achievement for the spiritual activities of human beings, which can be used for life, material production, or even the spiritual area of human beings. Cultural industry should not only generate economic benefit, as its social benefit is more important. Therefore, cultural product should guide active values, and give full play to its functions, such as beneficial to intelligence, enlightenment function, cohesion function, and aesthetic function. Only in this way, can it really create the cultural products that are favored by the public at the seeing or hearing, and even obtain more financing opportunities. The content of cultural products should concentrate more on the healthy development of national culture, carry forward the times spirit, and shape the positive humanistic character. Cultural crowdfunding platform should effectively screen cultural projects, and recommend those cultural products that can reflect the characteristics of the times, and with active values to investors. As consumers or investors of cultural products, they should have strong aesthetic ability, as well as positive values orientation. As a government, it should guide the whole society to build a relatively stable social value appraisal system, as well as evaluate and guide cultural production and consumption. Social values can be measured in accordance with some standards, such as historical standard, public standard, group standard, and expert standard, until it has formed a social value evaluation system in the form of law. The evaluation activity of social values is usually forced to exert the function through the form of public vote and national legislation. For instance, the behavioral guidance from government policies, punishment from national laws after the activity, and moral compelling from public opinions are some common forms for the law of social values to bring into play [9].

\section{Conclusions}

The projects in cultural industry with creativeness will be easily concerned by the market. Cultural creative 
crowdfunding was originated from the American website Kickstarter (2009), and then foreign crowdfunding achieved rapid development. The earliest crowdfunding website in China was Name Call (2011). The projects in numerous crowdfunding platforms mainly focus on film, music, publication, animation, design and games, which have successfully raised fund for many cultural creative projects. Cultural products should guide positive values.

It is very important to construct a favorable ecological environment for the "crowdfunding" of cultural industry. Policies and regulations on cultural crowdfunding will be gradually consummated; crowdfunding platform should pay attention to control risks, and strive to find its ecological niche; creators will continuously create cultural products that are favored by the public based on the characteristics of the times. Meanwhile, investors will be more rational for learning investment knowledge. Cultural and creative industry park is the cradle for the development of cultural industry. Crowdfunding in cultural industry will welcome a widespread market.

\section{References}

[1] Yang, D. and Su, L.G. (2014) Operation Model and Risk Prevention of Equity Crowdfunding Platform. Journal of National Procurators College, 7, 157-168. http://dx.doi.org/10.3969/j.issn.1004-9428.2014.04.017

[2] Huang, J.Q. and Xin, Q.L. (2013) Concept, Characteristics, and Enlightenments of "Crowdfunding”-A New Type of Network Financing Model. International Finance, 9, 64-69.

[3] Wu, Z.G., Song, P.C. and Zhao, J. (2014) Supervision on Capital Market-Enlightenment from the Supervision of American Crowdfunding. Credit Investigation, 4, 88-92. http://dx.doi.org/10.3969/j.issn.1674-747X.2014.03.020

[4] Fan, J.C. (2013) Study on Crowdfunding Business Model. Enterprise Economy, 8, 72-75.

[5] Wang, A.N. (2014) Operation Model and Risk Analysis for Crowdfunding. Journal of Finance and Economics Theory, 3, 99-103.

[6] Zhang, W. and Zhou, L.Z. (2006) Existing Problems and Basic Countermeasures for Investment and Finance in Chinese Cultural Industry. Modern Communication, 4, 106-112. http://dx.doi.org/10.3969/j.issn.1007-8770.2006.04.032

[7] Aitamurto, T. (2011) The Impact of Crowdfunding on Journalism. Journalism Practice, 4, 429-445.

[8] Meng, Q.J. and Wu, J.P. (2010) The Enterprise Ecological Niche Problem and Their Ecological Countermeasures in Complicated Environment. 2010 International Conference on Internet Technology and Applications, Wuhan, 20-22 August 2010, 1-5. http://dx.doi.org/10.1109/itapp.2010.5566471

[9] Zhang, Z.F. and Zhang, L.P. (2002) On Cultural Industry and Its Operation Laws. Social Science in China Press, 2 , 98-106. 